\title{
BMJ Open Radiofrequency denervation for chronic back pain: a systematic review and meta-analysis
}

\author{
Mary Elizabeth Chappell (D) , ${ }^{1}$ Raj Lakshman, ${ }^{1,2}$ Patrick Trotter, ${ }^{3}$ Mark Abrahams, ${ }^{3}$ \\ Michael Lee ${ }^{4}$
}

To cite: Chappell ME, Lakshman R, Trotter P, et al. Radiofrequency denervation for chronic back pain: a systematic review and meta-analysis. BMJ Open 2020;10:e035540. doi:10.1136/ bmjopen-2019-035540

- Prepublication history and additional material for this paper are available online. To view these files, please visit the journal online (http://dx.doi. org/10.1136/bmjopen-2019035540).

Received 05 November 2019

Revised 15 May 2020

Accepted 29 May 2020

A Check for updates

(c) Author(s) (or their employer(s)) 2020. Re-use permitted under CC BY-NC. No commercial re-use. See rights and permissions. Published by BMJ.

${ }^{1}$ Public Health Directorate, Cambridgeshire County Council, Cambridge, UK

${ }^{2}$ Medical Research Council Epidemiology Unit, University of Cambridge, Cambridge, UK ${ }^{3}$ Department of Pain Medicine, Cambridge University Hospitals NHS Foundation Trust,

Cambridge, UK

${ }^{4}$ Division of Anaesthesia, University of Cambridge, Cambridge, UK

\section{Correspondence to} Dr Mary Elizabeth Chappell; mary.chappell@cambridgeshire. gov.uk

\section{ABSTRACT}

Objectives To assess the effectiveness of radiofrequency denervation (RD) of lumbosacral anatomical targets for the management of chronic back pain.

Design Systematic review and meta-analysis of randomised controlled trials (RCTs).

Methods A database search (Medline, Medline in Process, Embase, CINHAL and the Cochrane library) was conducted from January 2014 to April 2019 for placebo or no-treatment controlled trials of RD for the management of chronic back pain. Included trials were quality assessed using the Cochrane Risk-of-Bias Tool and the quality of outcomes assessed using the Grading of Recommendations, Assessment, Development and Evaluations (GRADE) approach. Meta-analysis was conducted to calculate mean difference (MD) in posttreatment Pain Score.

Results Nineteen RCTs were included in the review. There appears to be short-term pain relief (1-3 months) provided by $\mathrm{RD}$ of the sacroiliac joint (five trials, $\mathrm{MD}-1.53$, $\mathrm{Cl}-2.62$ to 0.45 ) and intervertebral discs (four trials, MD $-0.98, \mathrm{Cl}-1.84$ to 0.12 ), but the placebo effect is large and additional intervention effect size is small $(<1$ on an 11 point (0-10) Pain Scale). Longer-term effectiveness (>6 months) is uncertain.

Conclusions $\mathrm{RD}$ of selected lumbosacral targets appears to have a small, short-term, positive effect for the management of patients with chronic back pain. However, the quality of evidence for the majority of outcomes is low or very low quality and there is still a degree of uncertainty, particularly around the duration of effect.

\section{INTRODUCTION}

Back pain is an extremely common symptom experienced by people of all ages, and can be attributed to a wide variety of disease processes. ${ }^{12}$ Low back pain is now the leading cause of disability worldwide and back pain is associated with a substantial economic burden, with high medical and societal costs. ${ }^{3}$ Studies have shown that a large proportion of medical costs come from hospital admissions and physical therapy for the management of back pain. ${ }^{4}$ However, there are also indirect costs associated with chronic or recurrent back pain that are difficult to quantify relating

\section{Strengths and limitations of this study}

This review brings together a number of recent trials with earlier trials so that there is a sizeable sum of evidence on which to assess the effectiveness of radiofrequency denervation (RD) for back pain.

Due to the invasive nature of the procedure, it is difficult to perform truly patient or provider-blinded trials and this brings some uncertainty around findings.

- There is limited reporting of long-term outcomes ( $>6$ months) for the effectiveness of RD.

to work absenteeism and related productivity. ${ }^{13}$ In many cases, back pain is nonspecific, or structural pathology amenable to surgical correction cannot be identified. ${ }^{5-7}$ Hence, patients and practitioners continue to seek non-surgical alternatives for the management of back pain.

Radiofrequency denervation (RD) involves the application of an alternating electric current $(250-500 \mathrm{kHz})$ via a needle probe to induce a highly localised rise in tissue temperature at the needle tip. ${ }^{8}$ The needle tip is usually placed under fluoroscopic guidance to enable selective ablation of sensory nerve branches that supply facet joints, sacroiliac joint or other structures that comprise the lumbosacral spine. RD would, therefore, offer relief of pain by attenuating sensory signals from the lumbosacral spine. ${ }^{9}$

Despite its use for over 20 years, ${ }^{10}$ the effectiveness of RD targeted at the anatomy of the lumbosacral spine is not yet established, with randomised controlled trials (RCTs) continuing to be performed. A number of trials have been published since the publication of the last high-quality review in $2015^{11}$ and our systematic review aimed to bring together this evidence in an attempt to evaluate whether RD is an effective intervention for the management of chronic non-specific back pain. 


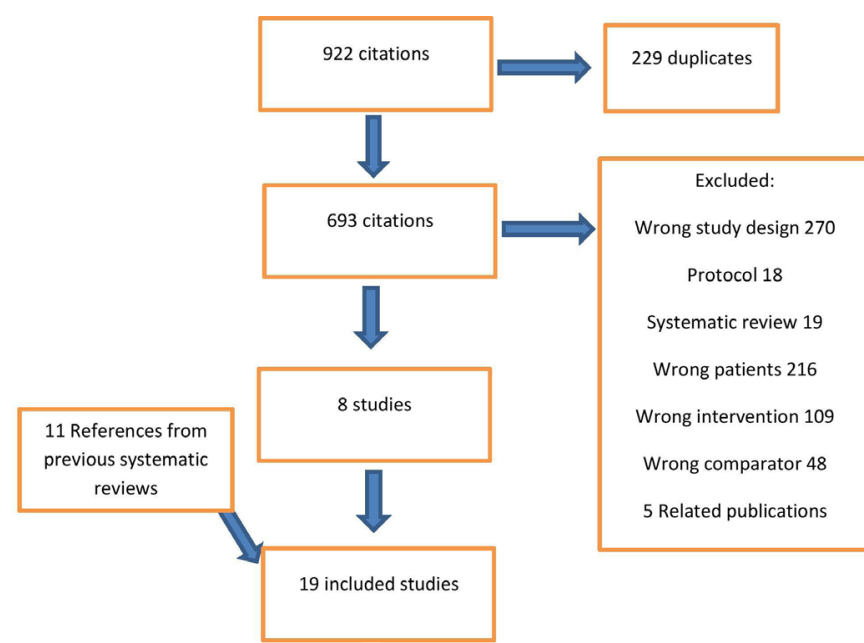

Figure 1 Preferred Reporting Items for Systematic Reviews and Meta-Analyses flow diagram.

\section{MATERIALS AND METHODS}

\section{Search strategy}

A search was conducted in Medline, Medline in Process, Embase, CINHAL and the Cochrane library from January 2014 to April 2019 (online supplementary appendix 1). Previous systematic reviews were used to obtain additional relevant studies published before 2014 .

\section{Inclusion criteria}

RCTs comparing RD of the spine with a control in patients with back pain with or without sciatica were included. Only trials of radiofrequency procedures for the purpose of ablating or denaturing sensory nerve branches or nociceptors that supply the lumbosacral spine were considered for inclusion. Trials of pulsed Radiofrequency (RF), ${ }^{12}$ or other forms of 'neuromodulatory' procedures that do not aim to ablate or denature these targets, were excluded from the review. Control groups where there was no active treatment were considered for inclusion but trials with potentially effective comparators, for example, corticosteroid injections, were excluded. Only trials of patients with back pain without a definite or surgically remediable cause (chronic non-specific back pain) were included in the review. The outcome for the review was patientreported Pain Score, for example, Visual Analogue Scale or Numeric Rating Scale.

\section{Data collection and quality assessment}

Trial characteristics were recorded from included studies. Study results were extracted independently by two authors (MEC and PT), with any disagreements resolved by consensus. The overall strength of evidence was assessed using the GRADE approach. ${ }^{13}$ Risk of bias was assed using the Cochrane Risk-of-Bias Tool. ${ }^{14}$ Any outcome where more than half of trials were considered to have a high or unclear risk of bias was downgraded. Outcomes were also downgraded where heterogeneity in the meta-analysis was greater than $50 \%$. Optimal sample size was taken to be 85 participants per study arm (as calculated in the Juch et al trial $)^{15}$ and studies with less than 170 participants, and/or where the $95 \%$ CIs included the line of no effect, were downgraded for imprecision. Publication bias was assessed using funnel plots and outcomes downgraded where there was a high certainty of publication bias.

\section{Data analysis}

Meta-analyses were conducted in RevMan ${ }^{16}$ with random effects models since the included studies investigated effectiveness in different population groups with varying intervention and control group treatments. Pain Score at 1-3 months was taken as the primary outcome (longest time point used for studies reporting multiple time points), allowing outcome from a larger number of studies to be combined. Pain Score data were reported on a 0-10-point scale (Visual Analogue Scale or Numeric Rating Scale) in all studies and the mean difference (MD) was, therefore, calculated without standardisation as done in the previous Cochrane review. ${ }^{11}$ Studies with different spinal targets, for example, facet joints, sacroiliac joints or intervertebral disc, were separated in the analysis. A sensitivity analysis was conducted to check the validity of findings by removing studies considered to have a particularly high risk of bias. Subgroup analysis to explore study heterogeneity was not conducted because of the small number of studies and high likelihood of reaching spurious conclusions.

\section{RESULTS \\ Study characteristics}

The search identified 922 citations of which 229 were duplicates. Studies were excluded as shown in figure 1. Of the 693 citations reviewed, 8 new trials were identified as well as 11 from a previous Cochrane review. ${ }^{11}$ Exclusions were made as shown in figure 1 . Nineteen trials were included in the review and their characteristics are shown in online supplementary appendix 2 . Trials investigated the effectiveness of RD of the facet joint (supplied by medial branch of the dorsal spinal ramus) ${ }^{15}{ }^{17-24}$ the sacroiliac joints, ${ }^{1525-28}$ the intervertebral discs ${ }^{29-33}$ or vertebral end plate (supplied by the basivertebral nerve). ${ }^{34}$ The majority of trials used a sham-control group but one large trial compared RD with no treatment (both groups received an exercise programme) and one small trial compared RD plus conventional medical with conventional medical management alone (including self-care, medications and physical and cognitive therapy).

\section{Study quality}

Sham-controlled trials generally appear to have conducted adequate randomisation but allocation concealment was often unclear. Processes were in place to blind patients and providers and outcome assessors. In some trials, maintenance of blinding was unclear as it was evident that patients undergoing sham procedures were offered $\mathrm{RD}$ in case of sham treatment failure. In these cases, blinding would have been broken. Most trials did not report dropouts and there was unclear risk of attrition 
Table 1 Results of the meta-analyses of randomised controlled trials

\begin{tabular}{|c|c|c|c|c|c|c|c|c|c|c|}
\hline & \multicolumn{5}{|c|}{ All trials } & \multicolumn{5}{|c|}{ Sham-controlled trials } \\
\hline & $\mathbf{k}$ & $\mathbf{N}$ & MD $(95 \% \mathrm{Cl})$ & $I^{2}$ & GRADE* & $\mathbf{k}$ & $\mathbf{N}$ & MD $(95 \% \mathrm{Cl})$ & $I^{2}$ & GRADE* $^{\star}$ \\
\hline \multicolumn{11}{|c|}{ RD of the facet joints } \\
\hline 6 months & 4 & 361 & $\begin{array}{l}-0.66 \\
(-1.37 \text { to } 0.05)\end{array}$ & $42 \%$ & Low & 3 & 110 & $\begin{array}{l}-1.05 \\
(-2.21 \text { to } 0.10)\end{array}$ & $32 \%$ & Low \\
\hline \multicolumn{11}{|c|}{ RD of the sacroiliac joints } \\
\hline $\begin{array}{l}1-3 \\
\text { months }\end{array}$ & 5 & 384 & $\begin{array}{l}-1.53 \\
(-2.62 \text { to } 0.45)\end{array}$ & $83 \%$ & Low & 4 & 156 & $\begin{array}{l}-1.89 \\
(-3.45 \text { to } 0.34)\end{array}$ & $87 \%$ & Very low \\
\hline 6 months & 1 & 228 & $\begin{array}{l}-0.28 \\
(-1.00 \text { to } 0.44)\end{array}$ & NA & Low & & & & & \\
\hline \multicolumn{11}{|c|}{ RD of the intervertebral discs } \\
\hline $\begin{array}{l}1-3 \\
\text { months }\end{array}$ & 4 & 200 & $\begin{array}{l}-0.98 \\
(-1.84 \text { to } 0.12)\end{array}$ & $40 \%$ & Low & 3 & 144 & $\begin{array}{l}-0.63 \\
(-1.36 \text { to } 0.10)\end{array}$ & $0 \%$ & Low \\
\hline 6 months & 3 & 127 & $\begin{array}{l}-1.74 \\
(-2.58 \text { to } 0.91)\end{array}$ & $0 \%$ & Low & 2 & 75 & $\begin{array}{l}-1.63 \\
(-2.58 \text { to } 0.68)\end{array}$ & $0 \%$ & Low \\
\hline 12 months & 1 & 20 & $\begin{array}{l}-1.70 \\
(-3.63 \text { to } 0.23)\end{array}$ & NA & Very low & 1 & 20 & $\begin{array}{l}-1.70 \\
(-3.63 \text { to } 0.23)\end{array}$ & NA & Very low \\
\hline \multicolumn{11}{|c|}{ RD of the vertebral body and end plate } \\
\hline 3 months & 1 & 205 & $\begin{array}{l}-0.34 \\
(-1.09 \text { to } 0.41)\end{array}$ & NA & Moderate & 1 & 205 & $\begin{array}{l}-0.34 \\
(-1.09 \text { to } 0.41)\end{array}$ & NA & Moderate \\
\hline
\end{tabular}

${ }^{*}$ GRADE assessment of the quality of the evidence.

$\mathrm{k}$, number of trials; MD, mean difference; $\mathrm{N}$, number of participants.

bias. The outcome for this review was Pain Score and this was reported in all trials and reporting bias was not considered to be an issue in the review. Four trials were identified as having high risk of bias and were removed in the sensitivity analysis. ${ }^{17192425}$

\section{Overall quality of the evidence}

The majority of outcomes were graded down for imprecision and all outcomes were downgraded for potential risk of bias. Consequently, almost all outcomes were graded as low quality. However, in some cases, high heterogeneity was also present and these outcomes were graded as very low quality. Publication bias was suggested by asymmetry in a number of the funnel plots. However, there was uncertainty due to the small numbers of studies and outcomes were not graded down for publication bias.

\section{Study findings}

The results of the meta-analyses are shown in table 1.
$\mathrm{RD}$ of the facet joints

Meta-analysis of Pain Scores at 1-3 months post procedure (longest time point used for studies with multiple time points) (marked on a $0-10$ scale) is shown in figure 2 and table 1 . The effect size was similar when all trials were included (seven trials, MD -0.56 , CI -1.13 to 0.01 ) or where just the sham-controlled trials were included (six trials, MD -0.63 , CI -1.39 to 0.12 ) but the effect was not significant for either. We also considered outcomes at 6 and 12 months, where data were available to explore longer term outcomes, but did not find any significant effect (table 1).

$\mathrm{RD}$ of the sacroiliac joints

Figure 3 shows the meta-analysis of trials for Pain Score at 1-3 months (longest time point used for studies with multiple time points). There was a significant effect of RD for the analysis including all trials (five trials, MD -1.53 , CI -2.62 to 0.45 ) or just sham-controlled trials (four trials, MD -1.89 , CI -3.45 to 0.34$)$. Only one trial ${ }^{15}$ assessed 


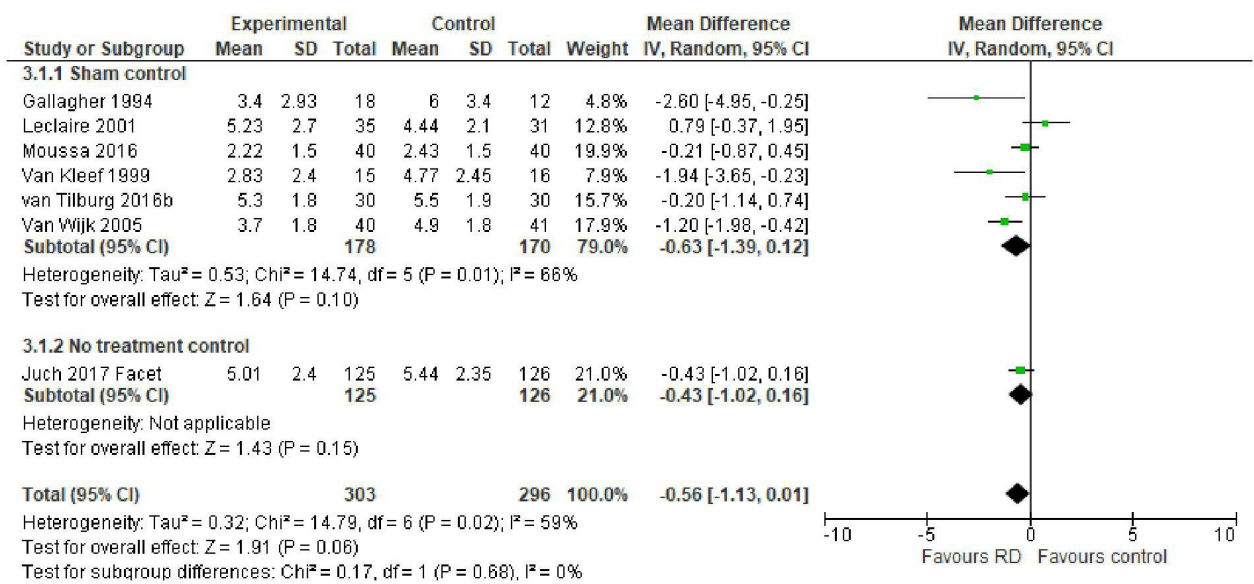

outcome at later time points and this showed no significant difference compared with a no-treatment control (table 1).

\section{$\mathrm{RD}$ of the intervertebral discs}

Pain Score at 1-3 months post treatment was significantly lower for RD compared with control in all trials (four trials, MD -0.98, CI - 1.84 to 0.12 ) but not for shamcontrolled trials alone (three trials, MD -0.63 , CI -1.36 to 0.10) (figure 4). Pain Score was significantly lower for RD when all trials and sham-controlled trials were considered at 6 months but, for one trial assessing outcome at 1 year, it was not (table 1$)$.

\section{$\mathrm{RD}$ of the vertebral body and end plate}

One trial of RD for vertebral body and end plate (basivertebral nerve ablation $)^{34}$ did not show significant benefits of RD compared with sham at 3,6 or 12 months (table 1 ).

\section{Sensitivity analysis}

Four studies were removed in the sensitivity analysis due to a high risk of methodological bias ${ }^{17192425}$ and the two non-sham-controlled trials were also removed. ${ }^{15} 32$ After the removal of these trials, outcome at 1-3 months for facet joint sham trials was still not significant (four trials, MD -0.57 , CI -1.60 to 0.46 ) and 1-3 month outcome for sacroiliac sham trials became non-significant (three trials, MD $-1.21, \mathrm{CI}-2.59$ to 0.16 ). The facet joint sham trial outcome at 6 months also became non-significant (one trial, MD 0.18, CI -2.80 to 3.16).

\section{DISCUSSION}

\section{Main findings}

This systematic review presents evidence suggesting that $\mathrm{RD}$ of the lumbosacral spine may have a small positive but short-lived effect in patients with chronic back pain, depending on the precise part of the anatomy that is being targeted by the procedure. The quality of evidence for the majority of findings is low or very low quality and there is still a degree of uncertainty around this assertion, particularly around the duration of effect. The size of benefit appears to be small $(<1$ point on a $0-10$ Pain Scale) and there are limited data for outcomes beyond 6 months. These assertions apply to RD for sacroiliac joints, whereas evidence for benefit to other targets is more limited. RD for facet joints did not show a significant benefit on 1-3-month outcome. There is a suggestion that there may be a benefit of RD for intervertebral discs but there is some inconsistency, with insignificant effect for short-term outcomes.

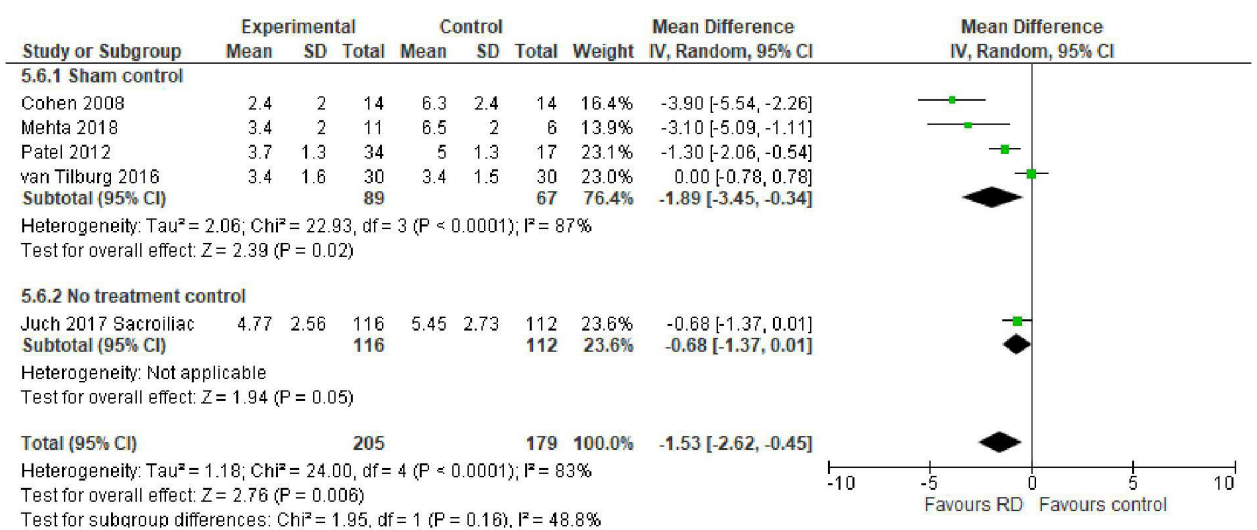

Figure 3 Post-treatment Pain Score for radiofrequency denervation of the sacroiliac joints versus control at 1-3-month followup (longest time point used for studies with multiple time points). 


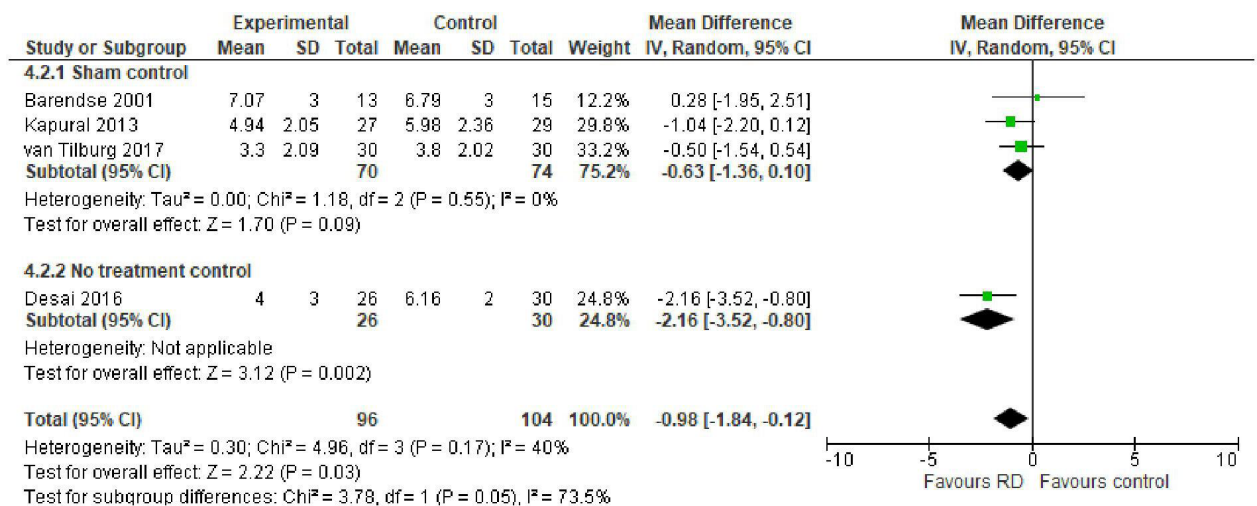

Figure 4 Post-treatment Pain Score for radiofrequency denervation of the intervertebral discs versus control at 1-3-month follow-up (longest time point used for studies with multiple time points).

What is also clear from the review is that both treatment and sham/no-treatment groups improved during the trials. In the sham-controlled trials, this may, in part, be due to placebo effect. However, the large trial by Juch et $a l^{15}$ used a 'no additional treatment' control (both groups received an exercise programme) but all study arms improved over time. This may be because a high proportion of control study participants actually received RD $(\sim 30 \%)$ due to crossover during the trial. However, this may also be explained by self-selection of participants who volunteer for research trials, ${ }^{35}$ and hence are likely to make more of an active effort to manage their back pain. Such participants may be more likely to engage with, and be diligent in, exercise programmes and seek medical assistance where needed.

In the trial by Juch et al, control group improvements may also be explained by the conservative management that they received. The exercise programme employed was multidisciplinary and comprised individual sessions over 8-12 hours focused on quality of movement and behaviour, with access to psychological care. There is evidence suggesting that patients with chronic back pain can benefit from pain management programmes that are of sufficient quality and duration. ${ }^{36}$ Where patients have not received an adequate trial of conservative therapy, they may benefit from further exercise programmes and other conservative management. It remains unclear whether patients who are either unable or unwilling to engage with conservative approaches to pain management would benefit from RD-based interventions as a first-line or isolated modality of treatment. Hence, there should be some reservation when considering the use of $\mathrm{RD}$ treatment as a first-line or isolated modality of pain management.

Regression to the mean may also have played a role in control group improvements since patients in the trial were recruited with elevated pain, responsive to an anaesthetic block. Back pain has been shown to have a varied aetiology, with some patients experiencing fluctuating levels of pain over time, while other experience constant high levels of pain. ${ }^{37} 38$ For the majority of trials that reported it, duration of back pain in participants prior to enrolment was 2-5 years and a proportion of these was likely to have had high levels of constant pain. Some, however, may have been experiencing fluctuating or recurrent pain within this period since the actual inclusion criteria for most trials was pain for $>3$ or 6 months based on patient recall. If they were recruited at a point where their pain had flared acutely, there would be a natural tendency for that painful episode to resolve over time.

\section{Strengths and limitations}

A major strength of this review is that it collates a larger body of evidence than previous systematic reviews, with the addition of a number of recent trials and thorough assessment of the quality of the evidence. The review is able to tentatively answer the question about the effectiveness of RD for back pain; an assertion that, to date, has proved to be very difficult due a paucity of evidence in this field.

This review uses evidence from a previous Cochrane review ${ }^{11}$ but the inclusion criteria for our review had a narrower scope (included only sham-controlled trials or conservative management-controlled trials of conventional neuroablative RD). Since the previous review appears to be of high quality, and we updated it with a thorough search of the literature to date, there is assurance that all relevant trials were included.

A limitation of this review is that it was difficult to truly assess risk of bias in trials included in the review. Trial integrity rested heavily on the blinding of participants and the outcome was likely to be highly subject to patients' preconceptions of the different interventions given. Most trials did not report information that providers gave to the patients about the different possible treatment arms, for example, did providers suggest to patients that RD was the effective treatment and that sham or no treatment would be ineffective? Where blinding was broken, these viewpoints may have influenced patients' response. In some of the sham-controlled studies, this was clearly evident. For example, in some studies, before randomisation, patients were told that, if randomised to sham, they could receive $\mathrm{RD}$ if they gained no benefit. Where 
blinding was broken, these opinions were likely to influence patients' perception of their pain. In other studies, information from providers was not reported and it is difficult to assess whether this type of bias occurred.

The review may also be limited in its ability to ascertain the technical quality of individual research trials. Even when examining the reported trial methodology, it is difficult to conclusively identify trials that employed procedures that may be more or less successful in denervating the specific lumbosacral anatomy. Some aspects of RD procedures in earlier trials are considered outdated ${ }^{39} 40$ but the advantages of more recent procedures for RD remain unproven, and there is no clear evidence of their superiority. Sensitivity analysis based on technical quality was, therefore, considered unhelpful and not performed.

The review is also limited by the lack of long-term data from trials. Most studies do not attempt to blind patients for more than 3 months and the longer follow-up outcomes are considered to be at higher risk of bias. It is still, therefore, unclear whether RD of lumbosacral anatomy has long-term benefits for back pain.

Finally, the review is limited in its ability to identify any aspects of patient or intervention characteristics that may make RD treatment more likely to be beneficial. There is, to date, no reliable predictor of benefit on back pain for RD procedures based on clinical or imaging findings or diagnostic injections. ${ }^{41}$ The relative advantages of different RD technologies used in included trials (eg, 'cooled'25 2632 and 'bipolar, ${ }^{30} 32 \mathrm{RD}$ ) remain to be established. Due to the small number of studies at each time point, subgroup analysis was not considered appropriate. However, the publication of more sham-controlled trials and trials comparing different RD technologies may make this type of investigation possible. Technical advances and advances in knowledge and experience may allow for better selection of anatomical targets and patients for RD, and hence improve clinical outcomes. It is important that these developments are formally assessed and published.

In conclusion, within the limitations in this review and the published literature, there appears to be at least short-term benefit from RD of selected lumbosacral anatomical targets for chronic back pain. However, the mean size of effect appears to be small and, overall, clinical significance may be marginal. Hence, chronic back pain remains a highly challenging condition to treat.

Acknowledgements Thanks to Julie Aikens and Kerry Herbert at Hinchingbrooke Healthcare Library for their assistance in designing and running the search strategies for the review.

Contributors MEC contributed to the planning of this work, selected articles for inclusion, extracted data, quality assessed studies and drafted and redrafted the manuscript. RL contributed to the planning of this work, reviewed the manuscript and approved the final version. PT extracted data from the trials, reviewed the manuscript and approved the final version. MA contributed to the planning of this work, reviewed the manuscript and approved the final version. ML contributed to the planning of this work, reviewed the manuscript and approved the final version.

Funding RL is supported by the Medical Research Council (MC_UU_12015/2). ML is supported by AABGI Foundation project grant (RCZB/071).

Competing interests None declared.
Patient and public involvement Patients and/or the public were not involved in the design, or conduct, or reporting, or dissemination plans of this research.

Patient consent for publication Not required.

Provenance and peer review Not commissioned; externally peer reviewed.

Data availability statement All data relevant to the study are included in the article or uploaded as supplementary information. All data relevant to the study are included in the article or uploaded as supplementary information.

Open access This is an open access article distributed in accordance with the Creative Commons Attribution Non Commercial (CC BY-NC 4.0) license, which permits others to distribute, remix, adapt, build upon this work non-commercially, and license their derivative works on different terms, provided the original work is properly cited, appropriate credit is given, any changes made indicated, and the use is non-commercial. See: http://creativecommons.org/licenses/by-nc/4.0/.

\section{ORCID iD}

Mary Elizabeth Chappell http://orcid.org/0000-0002-3789-0727

\section{REFERENCES}

1 Hartvigsen J, Hancock MJ, Kongsted A, et al. What low back pain is and why we need to pay attention. Lancet 2018;391:2356-67.

2 Hoy D, Bain C, Williams G, et al. A systematic review of the global prevalence of low back pain. Arthritis Rheum 2012;64:2028-37.

3 Maniadakis N, Gray A. The economic burden of back pain in the UK. Pain 2000;84:95-103.

4 Dagenais S, Caro J, Haldeman S. A systematic review of low back pain cost of illness studies in the United States and internationally. Spine J 2008:8:8-20.

5 National Institute of Health and Care Excellence. Low back pain and sciatica in over 16S: assessment and management, 2016.

6 Chou R, Baisden J, Carragee EJ, et al. Surgery for low back pain: a review of the evidence for an American pain Society clinical practice guideline. Spine 2009;34:1094-109.

7 Chou R, Loeser JD, Owens DK, et al. Interventional therapies, surgery, and interdisciplinary rehabilitation for low back pain: an evidence-based clinical practice guideline from the American pain Society. Spine 2009;34:1066-77.

8 Kline M. Radiofrequency techniques in clinical practice. In: Waldman $\mathrm{SD}$, Winnie AP, eds. Interventional pain management. Philadelphia PA: Saunders, 1996.

9 Wray JK, Dixon B, Przkora R. Radiofrequency ablation, 2019.

10 Manchikanti L, Hirsch JA, Pampati V, et al. Utilization of facet joint and sacroiliac joint interventions in Medicare population from 2000 to 2014: explosive growth continues! Curr Pain Headache Rep 2016;20:58.

11 Maas ET, Ostelo RWJG, Niemisto L, et al. Radiofrequency denervation for chronic low back pain. Cochrane Database Syst Rev 2015;26.

12 Brandon R, Cohen D, Edward T, et al. Pulsed radiofrequency neuromodulation in interventional pain Management-a growing technology. J Radiol Nurs 2018;37:181-7.

13 Schünemann H, Brożek J, Guyatt G, et al. Grade handbook: handbook for grading the quality of evidence and the strength of recommendations using the grade approach, 2013.

14 Higgins JP, Savovic J, Page MJ, et al. Revised cochrane risk-of-bias tool for randomized trials (rob 2, 2019.

15 Juch JNS, Maas ET, Ostelo RWJG, et al. Effect of radiofrequency denervation on pain intensity among patients with chronic low back pain: the MINT randomized clinical trials. JAMA 2017;318:68-81.

16 Review Manager. (RevMan) [Computer program]. version 5.3. Copenhagen: The Nordic Cochrane Centre, The Cochrane Collaboration, 2014.

17 Gallagher J, Petriccione di Vadi P, Wedley J, et al. Radiofrequency facet joint denervation in the treatment of low back pain: a prospective controlled double-blind study to assess its efficacy. Pain Clin 1994;7:193-8.

18 Leclaire R, Fortin L, Lambert R, et al. Radiofrequency facet joint denervation in the treatment of low back pain: a placebo-controlled clinical trial to assess efficacy. Spine 2001;26:1411-6.

19 Moussa WMM, Khedr W. Percutaneous radiofrequency facet capsule denervation as an alternative target in lumbar facet syndrome. Clin Neurol Neurosurg 2016;150:96-104.

20 van Kleef M, Barendse GA, Kessels A, et al. Randomized trial of radiofrequency lumbar facet denervation for chronic low back pain. Spine 1999;24:1937-42. 
21 van Tilburg CWJ, Schuurmans FA, Stronks DL, et al. Randomized sham-controlled double-blind multicenter clinical trial to ascertain the effect of percutaneous radiofrequency treatment for sacroiliac joint pain: three-month results. Clin J Pain 2016;32:921-6.

22 van Wijk RMAW, Geurts JWM, Wynne HJ, et al. Radiofrequency denervation of lumbar facet joints in the treatment of chronic low back pain: a randomized, double-blind, sham lesion-controlled trial. Clin J Pain 2005;21:335-44.

23 Nath S, Nath CA, Pettersson K, et al. Percutaneous lumbar zygapophysial (facet) joint neurotomy using radiofrequency current, in the management of chronic low back pain: a randomized doubleblind trial. Spine 2008;33:1291-7.

24 Tekin I, Mirzai H, Ok G, et al. A comparison of conventional and pulsed radiofrequency denervation in the treatment of chronic facet joint pain. Clin J Pain 2007:23:524-9.

25 Cohen SP, Hurley RW, Buckenmaier CC, et al. Randomized placebocontrolled study evaluating lateral branch radiofrequency denervation for sacroiliac joint pain. Anesthesiology 2008;109:279-88.

26 Patel N, Gross A, Brown L, et al. A randomized, placebo-controlled study to assess the efficacy of lateral branch neurotomy for chronic sacroiliac joint pain. Pain Med 2012;13:383-98.

27 van Tilburg CWJ, Stronks DL, Groeneweg JG, et al. Randomised sham-controlled double-blind multicentre clinical trial to ascertain the effect of percutaneous radiofrequency treatment for lumbar facet joint pain. Bone Joint J 2016;98-B:1526-33.

28 Mehta V, Poply K, Husband M, et al. The effects of radiofrequency neurotomy using a strip-lesioning device on patients with sacroiliac joint pain: results from a single-center, randomized, sham-controlled trial. Pain Physician 2018;21:607-18.

29 Barendse GA, van Den Berg SG, Kessels AH, et al. Randomized controlled trial of percutaneous intradiscal radiofrequency thermocoagulation for chronic discogenic back pain: lack of effect from a 90-second 70 C lesion. Spine 2001;26:287-92.

30 Kapural L, Vrooman B, Sarwar S, et al. A randomized, placebocontrolled trial of transdiscal radiofrequency, biacuplasty for treatment of discogenic lower back pain. Pain Med 2013;14:362-73.
31 van Tilburg CWJ, Stronks DL, Groeneweg JG, et al. Randomized sham-controlled, double-blind, multicenter clinical trial on the effect of percutaneous radiofrequency at the ramus communicans for lumbar disc pain. Eur J Pain 2017:21:520-9.

32 Desai MJ, Kapural L, Petersohn JD, et al. A prospective, randomized, multicenter, open-label clinical trial comparing intradiscal biacuplasty to conventional medical management for discogenic lumbar back pain. Spine 2016;41:1065-74.

33 Kvarstein G, Måwe L, Indahl A, et al. A randomized double-blind controlled trial of intra-annular radiofrequency thermal disc therapy-a 12-month follow-up. Pain 2009;145:279-86.

34 Fischgrund JS, Rhyne A, Franke J, et al. Intraosseous basivertebral nerve ablation for the treatment of chronic low back pain: a prospective randomized double-blind sham-controlled multi-center study. Eur Spine J 2018;27:1146-56.

35 The Cochrane Collaboration. Introduction to sources of bias in clinical trials. In: Cochrane Handbook for systematic reviews of interventions, 2011.

36 Morley S, Williams A, Hussain S. Estimating the clinical effectiveness of cognitive behavioural therapy in the clinic: evaluation of a CBT informed pain management programme. Pain 2008;137:670-80.

37 Dunn KM, Croft PR. Epidemiology and natural history of low back pain. Eura Medicophys 2004;40:9-13.

38 Dunn KM, Jordan K, Croft PR. Characterizing the course of low back pain: a latent class analysis. Am J Epidemiol 2006;163:754-61.

39 Dreyfuss P, Baker R, Leclaire R, et al. Radiofrequency facet joint denervation in the treatment of low back pain: a placebo-controlled clinical trial to assess efficacy. Spine 2002;27:556-7.

40 Juch JNS, Maas ET, Ostelo RWJG, Kapural L, Provenzano D, Narouze S, et al. Effect of radiofrequency denervation on pain intensity among patients with chronic low back pain: the MINT randomized clinical trials. JAMA 2017;318:68-81.

41 Cohen SP, Huang JHY, Brummett C. Facet joint pain--advances in patient selection and treatment. Nat Rev Rheumatol 2013;9:101-16. 